\title{
Procesos urbanos. presentación número 5
}

\author{
Urban Processes. Presentation of number 5 \\ Processos Urbanos 5. Apresentação do número 5
}

Pedro Arturo Martínez Osorio. M.Sc.

pedro.martinez@cecar.edu.co

(iD) https://orcid.org/0000-0002-9024-0918

Corporación Universitaria del Caribe - CECAR. Colombia

Con mucho gusto presento este número cinco de la revista científica Procesos Urbanos, adscrita a la Facultad de Ciencias Básicas, Ingeniería y Arquitectura de la Corporación Universitaria del Caribe - CECAR, Colombia. Gestión editorial que cumple con este 5 años de trabajo y mejora continua, con el objetivo de contribuir significativamente al conocimiento y desarrollo de la investigación científica en el área de la arquitectura, urbanismo, diseño y todas aquellas disciplinas que sean afines a la construcción colectiva de la ciudad, campo y territorio.

Para el presente número hemos reunido un grupo de artículos de gran interés que tocan diferentes problemáticas de gran pertinencia y actualidad, los cuales cuestionan aspectos de gran importancia para la construcción de un pensamiento crítico que posibilite el debate urgente sobre las formas de habitar en el siglo XXI.

El artículo que abre este número, es producto de una investigación sobre historia de la arquitectura, del M.Sc. historiador José Alexander Pinzón Rivera, denominado "origen y construcción de la Penitenciaria del Estado de Cundinamarca en la provincia de Bogotá (18321872)", expone los principales factores que dieron origen al proyecto para la penitenciaria de Bogotá, Colombia. Se identifican los lugares del proceso constructivo y la narración de los hechos entre la concepción del edificio en 1849 y los inicios de la fábrica en 1872. Siguiendo la línea de la investigación histórica, el segundo artículo denominado "importancia de Luis Llach Llostera para la evolución y desarrollo urbanístico y arquitectónico de Quibdó (1.920-1.947)" de los arquitectos Ph.D(c) Jhon Fredy Asprilla y Ph.D(c) Rafael Palmera, presenta los resultados de una investigación que indaga sobre la historia del desarrollo urbano y arquitectónico de la ciudad de Quibdó, Choco, Colombia. Se presenta la figura del Ingeniero Catalán Luis Llach LLostera quien fue de gran importancia en la transformación de esa ciudad. Se expone el proceso de su obra y la importancia de la misma en el contexto histórico en el que se materializó.

El tercer artículo "Importancia del Habitar en el pensamiento arquitectónico" de la arquitecta Ph.D. Joely Ariagny Sulbarán Sandoval, hace parte de una investigación que pretende desglosar la complejidad del pensamiento arquitectónico desde su origen en el habitar, a partir del enfoque hermenéutico, basándose en teorías de autores de gran trayectoria.

A continuación se presenta el artículo del arquitecto M,Sc, Jorge Correa Orozco, denominado "la vivienda mínima: una revisión del desarrollo del concepto en Colombia". Una investigación que revisa el concepto de vivienda mínima en Bogotá, toma como punto de partida las ideas del movimiento moderno, contrastándolas con la normatividad colombiana vigente, con el objetivo de evidenciar el decrecimiento paulatino que sufrió la vivienda de interés social en el proceso.

El artículo "proyecto urbano y ciudad a escala intermedia: Caso Distrito Medellín-Novation-Ruta N" de los arquitectos M.Sc. Elber José Cohen, M.Sc. Jorge Armando Díaz Marriaga y Ph.D(c) Walberto Badillo Jiménez, responde a la pregunta ¿cuál ha sido la evolución del concepto proyecto urbano de escala intermedia, y su implementación en la planificación de ciudades? muestran los aciertos de operaciones estratégicas para la recuperación, social, económica y cultural de áreas degradadas de sectores en centros urbanos, tomando como caso de estudio el distrito Medellín Innovation-Ruta-N, en Colombia.

A continuación se presenta un artículo del trabajador Social M.Sc. en Ciencia Política Christian Quinteros Flores, titulado "¿Es posible la justicia urbana en Chile?: análisis a la nueva institucionalidad en materia de mitigaciones y aportes al espacio público", en el cual se presenta la gobernanza como nuevo enfoque comprensivo de las dinámicas territoriales. Se observan aspectos normativos y conflictos territoriales en Chile, para realizar un análisis sobre los criterios de construcción de ciudad. 
El siguiente artículo, del arquitecto M.Sc. Rafael Hernández Urueta, denominado "segregación urbana en la ciudad de Sincelejo, Colombia: caso del barrio San Miguel", trata el fenómeno de segregación urbana, a partir de datos demográficos y sociales que muestran el origen y situación de un barrio periférico de la ciudad de Sincelejo Colombia.

A continuación se presenta el artículo "La necesidad de herramientas para la co-creación del paisaje urbano" del arquitecto M.Sc. Hans Intveen Pérez, quien presenta una herramienta para la extracción de información espacial desde la comunidad a través de patrones de diseño aplicables a la obra urbana. Como caso de estudio se sistematiza la experiencia de diseño participativo en la Región de Antofagasta en el marco del Programa de Recuperación de Barrios del Ministerio de Vivienda y Urbanismo.

El artículo "Estado Actual de la Planificación de las cuencas hídricas en el departamento de Sucre (Colombia)" hace parte de una investigación desarrollada por los ingenieros Esp. Angelina Hernández Arrázola, Esp. Keila Landero Madera y Ph.D. Juan Pablo Rodríguez Miranda, quienes revisan el estado de la planificación de las cuencas hídricas en el departamento de Sucre, Colombia, advierten la necesidad urgente de un ordenamiento del territorio que permita mantener o restablecer el equilibrio entre el aprovechamiento de los servicios ecológicos de las cuencas hídricas y el estado natural de las mismas.

Se presenta a continuación el artículo en portugués del Ph.D. Fernando José Da Silva, denominado "Análisis estructural de tres columnas de bambú y sus aplicaciones sostenibles en Arquitectura". Este trabajo hace parte de una investigación que desarrolla un análisis estructural experimental de tres diferentes columnas, denominadas híbrida, compuesta y haz utilizando barras de bambú de la especie Phyllostachys pubescens. Propone diferentes posibilidades de aplicación, donde genera interacciones entre las áreas de arquitectura, diseño e ingeniería.

En ese mismo sentido, el siguiente artículo del Post Ph.D. Carlos César Morales Guzmán, denominado "diseño de una cubierta hiperbólica plegable tensada", desarrolla un sistema flexible, en el que se propone una piel de tenso estructura que ayuda a crear una estructura fácil de transportar y construir en diversos lugares. La investigación se centra en procesar detalles experimentales y su diseño en 3D, para verificar su pertinencia en el diseño de uniones articuladas.

Para cerrar este número, un artículo en portugués de la diseñadora M.Sc. Joice Moretto, denominado "dibujo- expresional y creatividad: el pensamiento visual en beneficio del proyecto". Este trabajo hace parte de una investigación experimental que pretende contribuir con la cultura de la práctica del dibujo como herramienta auxiliar en la generación de ideas durante un proceso de resolución de problemas, con el objetivo de contribuir en el proceso de creación en áreas como la arquitectura y el diseño.

Estamos convencidos que estos artículos y las reflexiones que se plantean en cada uno de esos trabajos de investigación, serán de gran utilidad para ampliar la discusión en torno a la construcción de la ciudad y el territorio desde un enfoque transdisciplinar e interdisciplinar de la sostenibilidad en el siglo XXI. 